\title{
A convenient way for the synthesis of mono $\mathrm{N}$-alkylated ethanolamine
}

\author{
Zhe Li, Changren Yan
}

Advenchen Lab. LLC 887 Patriot Dr. STE A Moorpark, CA 93021 USA

\begin{abstract}
N$-alkylated ethanol amines, especially the $N$-monoalkylated ethanol amines, feature widely applications in industries. This manuscript would introduce a new methodology to prepare $N$-monoalkylated ethanol amine derivatives that could avoid potential side reactions forming $N, N$-dialkylated by-products.
\end{abstract}

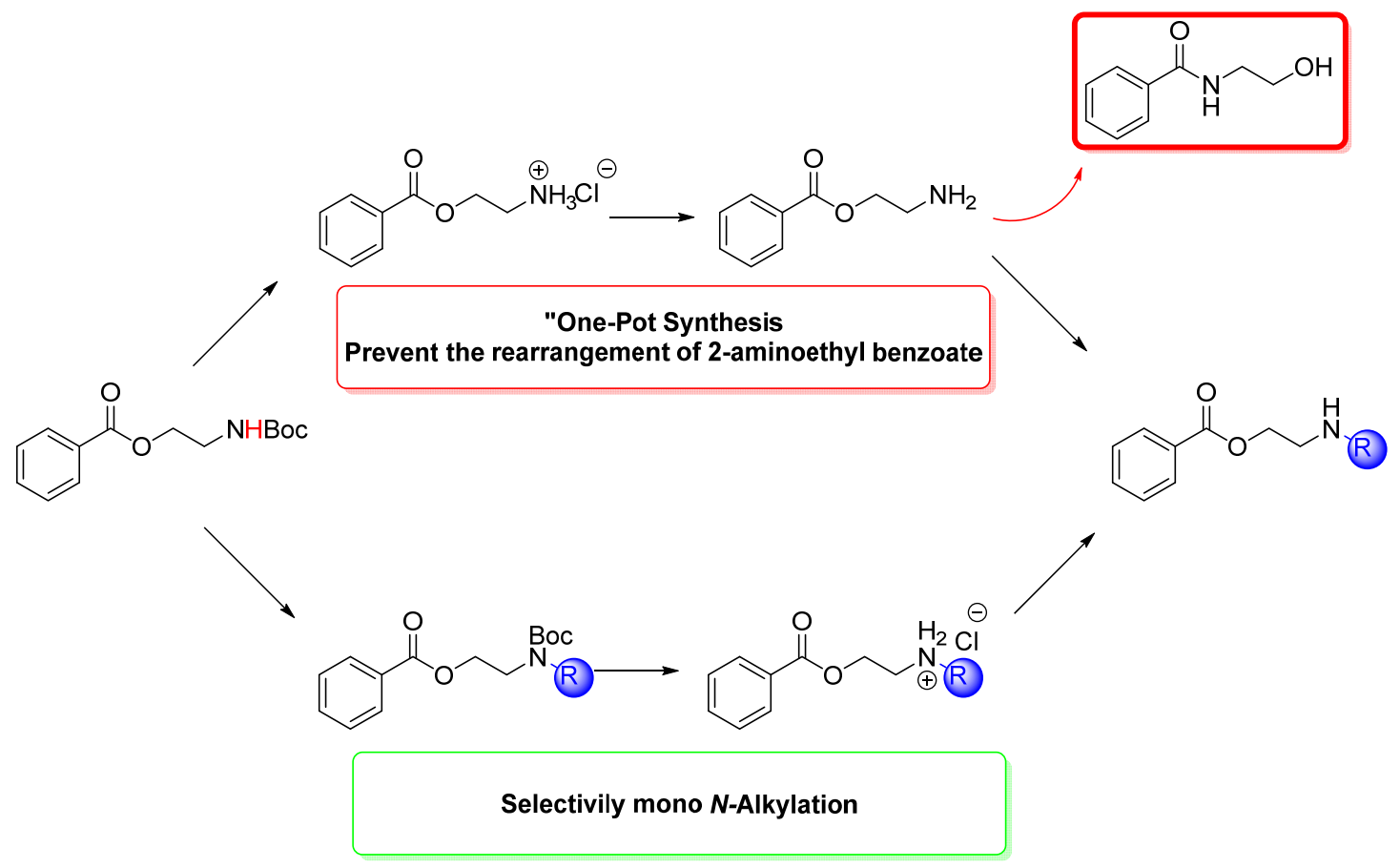

\section{Introduction}

$\mathrm{N}$-alkylated ethanol amines are a series of amino alcohol derivatives that equipped with a secondary or tertiary nitrogen atom altogether with at least one hydroxyl group in the same molecule. These type of compounds are usually liquid under room temperature and give the characteristic smell of amine ${ }^{1}$.

$N$-alkylated ethanol amine derivatives feature widely applications in industries, for example, the acidic gas absorbent for gas purification, the adductive chemical for paper and leather processing. Furthermore, ethanol amine derivatives feature important application in medicinal chemistry as they can be used as important intermediates in the synthesis for lots of drugs, especially for local anesthesia ${ }^{2}$. 
Due to the chemical properties of two protons on the $\mathrm{NH}_{2}$ group of ethanol amines are identical. The most commonly reported $N$-alkylation techniques of ethanol amine are just using excess amount of alkylation agent to obtain $N, N$-dialkylated ethanol amines. Compared with $N, N$-dialkylation, the acquirement of $N$-monoalkylated ethanol amines faces more difficulty. The commonly used technique for this is just trying to accurately control the reaction temperature and the amount of alkylation agent to make the majority product is the $\mathrm{N}$-monoalkylated product. Obviously, this technique cannot completely suppress the formation of $N, N$-dialkylated ethanol amine by-product and a subsequent purification is mandatory for the access of pure $N$-monoalkylated ethanol amine.

Recently, numerous investigations on selective $N$-alkylation of amines with alcohols ${ }^{3-7}$ or carboxylic acid ${ }^{8,9}$ were reported. However, these new methodologies always involved the usage of catalysts that were expensive or (and) hard to prepare, which dramatically hindered their application in industries.

\section{Results and discussion}

In this research, we would like to introduce a novel methodology to synthesis $\mathrm{N}$ monoalkylated ethanol amine derivatives. To save time, a readily commercial available ethanol amine derivative, the $N$-Boc-ethanolamine was selected as the starting material. In $\mathrm{N}$-Boc-ethanolamine, one of the proton in the amine group is protected by Boc thus the remaining proton in the amine group or the hydroxyl group can be selectively functionalized. This new protocol was summarized in the scheme below (Scheme 1).

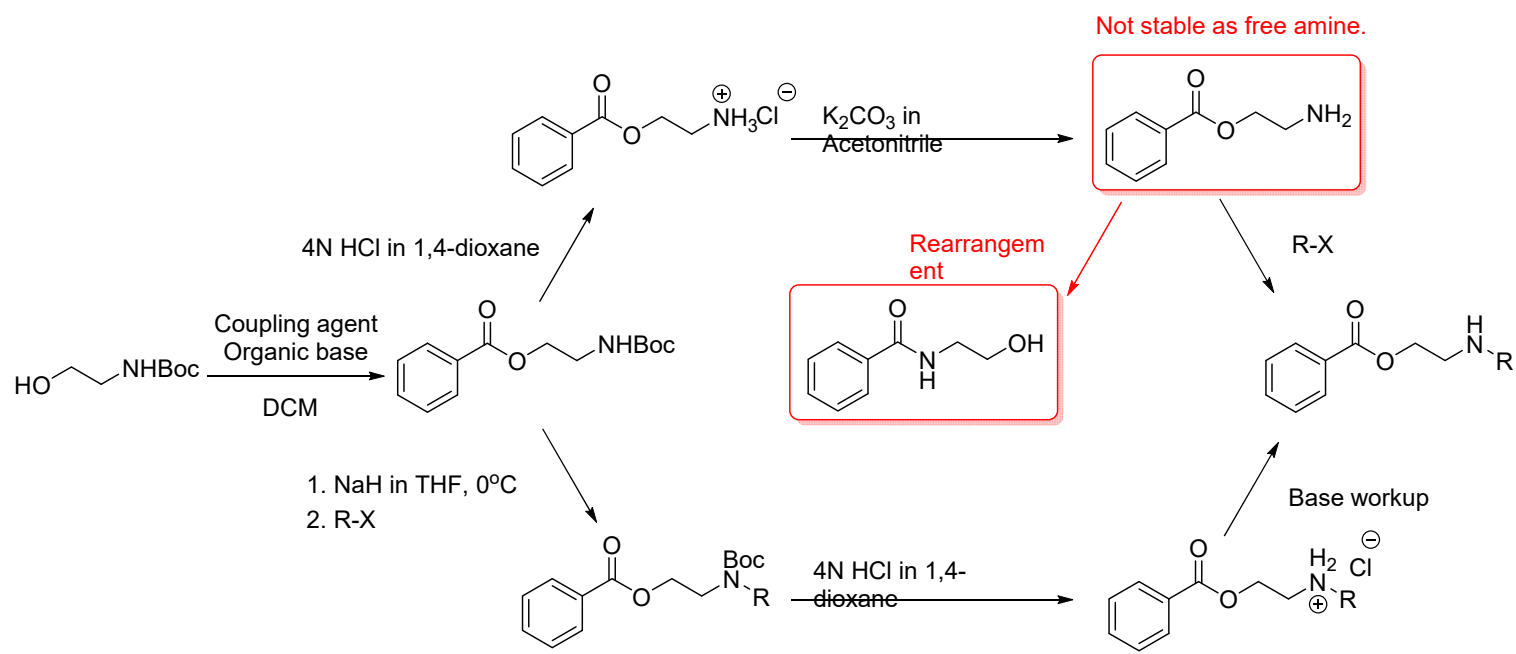

Scheme 1 Two routes for the synthesis of mono-N-alkylated 2-aminoethyl benzoates.

Getting started from $\mathrm{N}$-Boc-ethanolamine, the $\mathrm{OH}$ group was protected by using the benzoyl group. This action will not only prevent the hydroxyl group from undergoing side reactions, but also made the product feature UV absorption which allowed the following synthesis, especially the purification steps much more convenient. This conversion could be finished by treating $N$-Boc-ethanolamine with benzoic acid under the existence of an 
appropriate coupling agent (eg. $N, N^{\prime}$-dicyclohexylcarbodiimide ${ }^{10}$, 1-ethyl-3-(3dimethylaminopropyl)carbodiimide ${ }^{11-13}$ or carbonyldiimidazole ${ }^{14,15}$ ) and some kind of organic base (eg. trimethylamine or $N, N$-diisopropylethylamine) as acid scavenger, yielding 2-((tert-butoxycarbonyl)amino)ethyl benzoate as product in excellent yield ${ }^{16}$.

The cleavage of Boc protecting group can be done easily by treating with acids, especially strong acids, to form the corresponding salts of 2-aminoethyl benzoate. It was reported that this task can be finished by using trifluoroacetic acid (TFA) ${ }^{16}$. However, this methodology required long reaction time to finish (at room temperature for $16 \mathrm{~h}$ then at $40^{\circ} \mathrm{C}$ for $24 \mathrm{~h}$ ), which absolutely hindered its application. At here, we found that this mission can be accomplished efficiently within $2-3 \mathrm{~h}$ by treating with $4 \mathrm{~N} \mathrm{HCl}$ in dioxanes under room temperature, giving the 2-(benzoxyloxy)ethanaminium chloride as product. The resulting $\mathrm{HCl}$ salt was pure enough to be used in the following steps without further purification.

Initially, we attempted to use common strong inorganic base such as $\mathrm{NaOH}$ or $\mathrm{KOH}$ to convert the $\mathrm{HCl}$ salt 2-(benzoxyloxy)ethanaminium chloride to free amine 2-aminoethyl benzoate, which was used to perform further $N$-alkylation reactions with various alkylation reagents. However, after multiple attempts, the alkylation reactions always gave very low yield or even did not proceed at all, which was abnormal for this type of reaction.

It was documented that if the 2-(benzoxyloxy)ethanaminium chloride was treated with triethylamine, a rearrangement reaction was observed, leading to $\mathrm{N}$-(2hydroxyethyl)benzamide as a rearranged product instead of desired target 2-aminoethyl benzoate $^{16}$. In our scenario, a similar reaction might occur. A proposed mechanism was shown as below (Scheme 2). After the removal of $\mathrm{HCl}$ by treating with some kind of base, the free amine 2-aminoethyl benzoate was released. The lone pair of electron in $\mathrm{NH}_{2}$ group featured strong nucleophilicity and would like to attack the carbon atom in the $\mathrm{C}=\mathrm{O}$ double bond in the ester, forming a five-membered ring transition state. Meanwhile, the lone pair electron on the oxygen atom would like to attack the center carbon atom from the back of $\mathrm{C}-\mathrm{O}$ bond and opened the five-membered ring transition state. After a sequential intermolecule proton migration, the rearrangement product $N$-(2-hydroxyethyl)benzamide was obtained. It was well know that the $\mathrm{C}-\mathrm{N}$ bond in amide was much stronger than the $\mathrm{C}-\mathrm{O}$ bond in ester ${ }^{17}$, this intermolecular rearrangement could significant lower the molecular energy thus it could explain this reaction occurred spontaneously at room temperature.

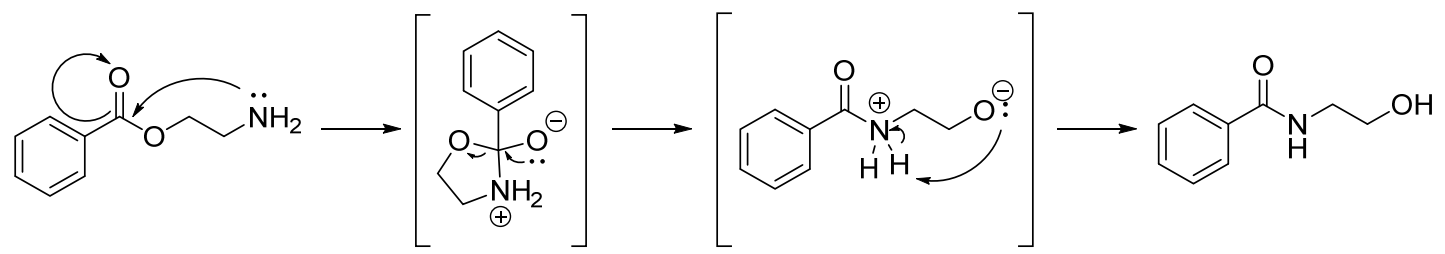

Scheme 2 Purposed mechanism for the rearrangement of 2-aminoethyl benzoate into $\mathrm{N}$-(2-hydroxyethyl)benzamide.

From the experimental results described above, it could be concluded that the $\mathrm{HCl}$ salt 2(benzoxyloxy)ethanaminium chloride was rather stable under room temperature whereas the corresponding free amine 2-aminoethyl benzoate would convert to $\mathrm{N}$-(2- 
hydroxyethyl)benzamide spontaneously. Fortunately, this rearrangement reaction was a relatively slow process. For this reason, a kind of "one-pot synthesis" was designed by adding 2-(benzoxyloxy)ethanaminium chloride, some kind of base and an alkylation reagent altogether into an appropriate solvent. This action would allow the free amine released by the base to react with alkylation reagent immediately before it suffer from the previous described rearrangement process.

By using this kind of "one-pot synthesis", we have successfully synthesized 2-((2fluoroethyl)amino)ethyl benzoate by heating 2-(benzoxyloxy)ethanaminium chloride, $\mathrm{K}_{2} \mathrm{CO}_{3}$ and 1-fluoro-2-iodoethane altogether in acetonitrile. The disadvantage of this methodology was still obvious. Although it was possible to control the ratio of 2(benzoxyloxy)ethanaminium chloride and the alkylation reagent to make the major product was 2-((2-fluoroethyl)amino)ethyl benzoate. However, the formation of $N, N$-dialkylation product 2-(bis(2-fluoroethyl)amino)ethyl benzoate could not be completely suppressed thus a further separation of mono/di alkylation products was still required (Scheme 3).

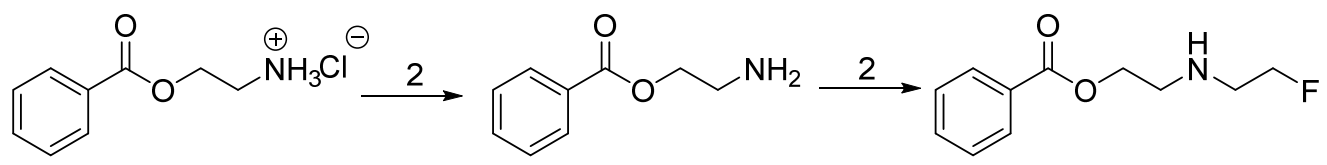

Scheme 3 "One-pot reaction" for the synthesis of 2-((2-fluoroethyl)amino)ethyl benzoate.

In chemical industry, the chemical reactions require sequential purification steps should always be avoided as these purification steps are always time-consuming and usually lead to dramatically shrink in the yield of desired product. On contrary, the chemical reactions could give specific single product are always welcome although additional reaction steps might require (eg. the addition and cleavage of protection groups).

To prevent the possible formation of dialkylation product, it might be a much better idea to do the alkylation reaction with the compound that one of the proton in the $\mathrm{NH}_{2}$ was shielded by a particular protection group whereas the other one was exposed. In the case of 2-((tert-butoxycarbonyl)amino)ethyl benzoate which was synthesized above, the protection group was tert-Butyloxycarbonyl (Boc). It was discovered in our lab that the NH proton in 2-((tert-butoxycarbonyl)amino)ethyl benzoate could be deprotonated by the treatment of a strong base (such as sodium hydride). The sequential addition of an alkylation reagent featured good leaving group (such as methyl iodide) could yield the $\mathrm{N}$ mono alkylated product (in the case of methyl iodide, the product was 2-((tertbutoxycarbonyl)(methyl)amino)ethyl benzoate).

The removal of Boc protection group could be done with previous described protocol efficiently (4N HCl in 1,4-dioxane under room temperature), yielding 2-(benzoyloxy)- $N$ methylethan-1-aminium chloride as the specific single alkylation product. 


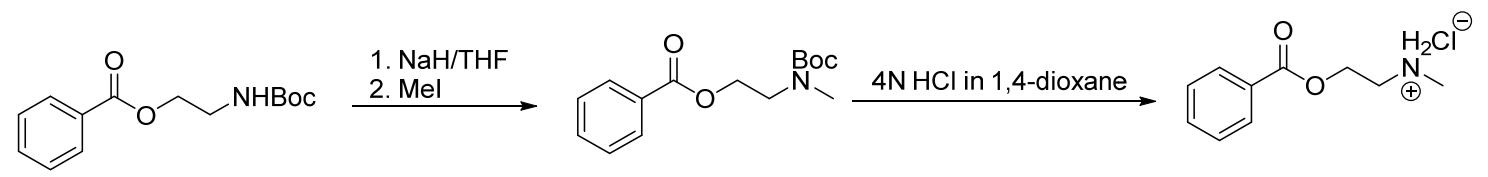

Scheme 4 Mono- $N$-alkylation via the deprotonation of Boc protected amine.

\section{Experimental section}

\section{2-((tert-butoxycarbonyl)amino)ethyl benzoate}<smiles>CC(C)(C)OC(=O)NCCOC(=O)c1ccccc1</smiles>

\section{Method 1:}

A $250 \mathrm{~mL}$ round bottom flask was charged with $N$-Boc-ethanolamine (10 g, $62 \mathrm{mmol})$, benzoic acid ( $8.5 \mathrm{~g}, 70 \mathrm{mmol}), \mathrm{EDC} . \mathrm{HCl}$ (15 g, $78 \mathrm{mmol})$, diisopropyleyamine $(24 \mathrm{~g}, 125$ mmol), DMAP $(0.76 \mathrm{~g}, 6.2 \mathrm{mmol})$ and DCM $(50 \mathrm{~mL})$. The resulting yellow solution was stirred at room temperature overnight. At that time, TLC indicated that a new product was formed and the solution was thoroughly washed by $1 \mathrm{M} \mathrm{HCl}(50 \mathrm{~mL}$ x 3$), 2 \mathrm{M} \mathrm{NaOH}(50$ $\mathrm{mL} \times 3)$ and brine $(50 \mathrm{~mL} \times 1)$. After dried with anhydrous sodium sulfate and concentrated to dryness, the crude product was purified with silica gel column chromatography (hexanes:EtOAc $=3: 1$ to 1:1), yielding white solid (12.6 g, $48 \mathrm{mmol}, 77 \%$ yield) as final product.

\section{Method 2:}

In a $250 \mathrm{~mL}$ round bottom flask, $N$-Boc-ethanolamine $(3.2 \mathrm{~g}, 20 \mathrm{mmol})$ and trimethylamine $(3.0 \mathrm{~g}, 30 \mathrm{mmol})$ were dissolved in dichloromethane $(40 \mathrm{~mL})$. This solution was then cooled to $0{ }^{\circ} \mathrm{C}$ in ice bath and benzoyl chloride $(3.1 \mathrm{~g}, 22 \mathrm{mmol})$ was added dropwised. After the addition was accomplished, the resulting was stirred at $0{ }^{\circ} \mathrm{C}$ for $1 \mathrm{~h}$, then at room temperature for another one hour. TLC indicated that a new product was formed and the solution was thoroughly washed by saturated $\mathrm{NaHCO}_{3}$ solution $(40 \mathrm{~mL} \times 1)$ and brine $(40$ $\mathrm{mL} \times 1$ ). After dried with anhydrous sodium sulfate, the solvent was removed by rotary evaporation and the crude product was purified with silica gel column chromatography (hexanes:EtOAc $=3: 1$ to $1: 1)$, yielding white solid $(4.5 \mathrm{~g}, 16 \mathrm{mmol}, 80 \%$ yield) as final product.

${ }^{1}$ H-NMR (300 MHz, DMSO-d6) $\delta: 8.002(\mathrm{~d}, J=7.5 \mathrm{~Hz}, 2 \mathrm{H}), 7.654$ (t, $\left.J=7.5 \mathrm{~Hz}, 1 \mathrm{H}\right)$, $7.516\left(\mathrm{~d}, J_{1}=7.5 \mathrm{~Hz}, J_{1}=7.5 \mathrm{~Hz}, 2 \mathrm{H}\right), 4.241(\mathrm{t}, J=5.4 \mathrm{~Hz}, 2 \mathrm{H}), 3.330$, (t, $J=5.4 \mathrm{~Hz}$, 2H), $1.369(\mathrm{~s}, 9 \mathrm{H})$.

${ }^{13} \mathbf{C}\left\{{ }^{1} \mathbf{H}\right\}$-NMR (75 MHz, DMSO-d6) $\delta$ : 165.664, 155.678, 133.162, 129.221, 128.484, 77.706, 63.852, 38.872, 28.107.

\section{2-(benzoxyloxy)ethanaminium chloride}


<smiles>[NH3+]CCOC(=O)c1ccccc1</smiles>

A $50 \mathrm{~mL}$ round bottom flask was charged with 2-((tert-butoxycarbonyl)amino)ethyl benzoate $(1.0 \mathrm{~g}, 3.8 \mathrm{mmol})$ follow by the addition of $4 \mathrm{~N} \mathrm{HCl}$ in dioxanes $(10 \mathrm{~mL}$, preprepared in ice bath). The resulting mixture was stirred under room temperature for 2 hours. Meanwhile, TLC showed starting material completely consumed and a new product with higher polarity was formed. After the removal of solvent by rotary evaporation, white crystals $(0.7 \mathrm{~g}, 3.5 \mathrm{mmol}, 92 \%$ yield) was formed as final product. This product was pure enough to be used in the following steps without further purification.

ESI-MS: $[\mathrm{M}+\mathrm{H}]^{+}=166.1,[\mathrm{M}+\mathrm{Na}]^{+}=188.2,[2 \mathrm{M}+\mathrm{H}]^{+}=331.5,[2 \mathrm{M}+\mathrm{Na}]^{+}=353.1$.

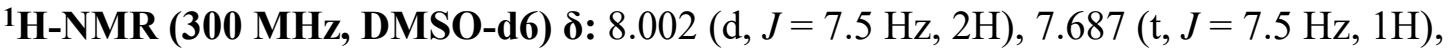
$7.545\left(\mathrm{~d}, J_{1}=7.5 \mathrm{~Hz}, J_{1}=7.5 \mathrm{~Hz}, 2 \mathrm{H}\right), 4.503(\mathrm{t}, J=5.1 \mathrm{~Hz}, 2 \mathrm{H}), 3.240,(\mathrm{~s}, 2 \mathrm{H})$.

${ }^{13} \mathbf{C}\left\{{ }^{1} \mathbf{H}\right\}-N M R$ (75 MHz, DMSO-d6) $\boldsymbol{\delta}:$ 165.546, 133.414, 129.630, 129.174, 128.489, $61.388,37.756$.

\section{2-((2-fluoroethyl)amino)ethyl benzoate}<smiles>O=C(OCCNCCF)c1ccccc1</smiles>

A $25 \mathrm{~mL}$ seal tube was charged with 2-(benzoxyloxy)ethanaminium chloride (500 $\mathrm{mg}, 2.5$ mmol), 1-fluoro-2-iodoethane (420mg, $2.4 \mathrm{mmol}), \mathrm{K}_{2} \mathrm{CO}_{3}(1.0 \mathrm{~g}, 2.5 \mathrm{mmol})$ and acetonitrile $(5 \mathrm{~mL})$. The resulting suspension was heated to $70{ }^{\circ} \mathrm{C}$ and stirred for 7 hours. At this stage, TLC indicated that the starting material was completely consumed and a new products with lower polarity was formed. The resulting suspension was filtered and the filtrate was diluted to a total of $25 \mathrm{~mL}$ with ethyl acetate and well washed with brine ( 25 $\mathrm{mL})$. Organic layer was dried over with anhydrous sodium sulfate and concentrated in vacuo. The resulting crude produce was purified with prep-TLC, yielding final product as colorless oil (310 mg, $1.5 \mathrm{mmol}, 60 \%$ yield).

ESI-MS: $[\mathrm{M}+\mathrm{H}]^{+}=212.0,[\mathrm{M}+\mathrm{Na}]^{+}=234.0$.

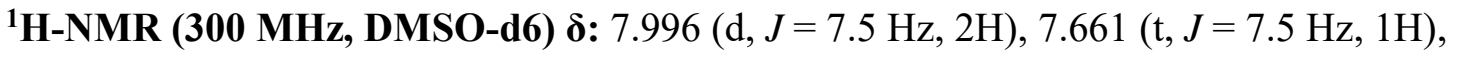
$7.531\left(\mathrm{~d}, J_{1}=7.5 \mathrm{~Hz}, J_{1}=7.5 \mathrm{~Hz}, 2 \mathrm{H}\right), 4.560(\mathrm{t}, J=5.1 \mathrm{~Hz}, 2 \mathrm{H}), 4.401(\mathrm{t}, J=5.1 \mathrm{~Hz}$, 2H), $3.562(\mathrm{t}, J=5.1 \mathrm{~Hz}, 2 \mathrm{H}), 2.940(\mathrm{t}, J=5.0 \mathrm{~Hz}, 2 \mathrm{H})$.

${ }^{13} \mathbf{C}\left\{{ }^{1} \mathbf{H}\right\}$-NMR (75 MHz, DMSO-d6) $\delta$ : 171.173, 133.207, 128.975, 128.699, 128.631, 66.162, 64.343, 58.488, 47.364.

\section{2-((tert-butoxycarbonyl)(methyl)amino)ethyl benzoate}


<smiles>CN(CCOC(=O)c1ccccc1)C(=O)OC(C)(C)C</smiles>

A nitrogen flushed $50 \mathrm{~mL}$ round bottom flask was charged with 2-((tertbutoxycarbonyl)amino)ethyl benzoate $(3.0 \mathrm{~g}, 11 \mathrm{mmol})$ and anhydrous THF $(10 \mathrm{~mL})$. Ther resulting solution was cooled to $0^{\circ} \mathrm{C}$ in ice bath and $\mathrm{NaH}(2.2 \mathrm{~g}, 55 \mathrm{mmol})$ was slowly added. After the addition was done, the suspension was continued to be stirred for half an hour in ice bath and methyl iodide $(4.8 \mathrm{~g}, 33 \mathrm{mmol})$ was charged. The resulting mixture was stirred at $0^{\circ} \mathrm{C}$ for one hour then at room temperature for one hour. TLC indicated that the starting material was completely consumed and a new products with lower polarity was formed.

The resulting mixture was diluted with ethyl acetate $(\sim 20 \mathrm{~mL})$ and the excess amount of $\mathrm{NaH}$ was quenched with saturated $\mathrm{NaHCO}_{3}$ solution. Organic layer was dried over with anhydrous sodium sulfate and concentrated in vacuo. Crude product was loaded on the top of a silica gel column to elute, yielding pure product as colorless oil $(2.3 \mathrm{~g}, 8.2 \mathrm{mmol}, 74 \%$ yield).

ESI-MS: $[\mathrm{M}+\mathrm{H}]^{+}=280.3$.

${ }^{1}$ H-NMR (300 MHz, DMSO-d6) 8: 7.971 (d, $\left.J=7.5 \mathrm{~Hz}, 2 \mathrm{H}\right), 7.661$ (t, $\left.J=7.5 \mathrm{~Hz}, 1 \mathrm{H}\right)$, $7.526\left(\mathrm{~d}, J_{1}=7.5 \mathrm{~Hz}, J_{1}=7.5 \mathrm{~Hz}, 2 \mathrm{H}\right), 3.561(\mathrm{t}, J=5.2 \mathrm{~Hz}, 2 \mathrm{H}), 3.409(\mathrm{t}, J=5.1 \mathrm{~Hz}$, 2H), 3.248 (s, 3H), $1.391(\mathrm{~s}, 9 \mathrm{H})$.

${ }^{13} \mathbf{C}\left\{{ }^{1} \mathbf{H}\right\}$-NMR (75 MHz, DMSO-d6) $\delta$ : 165.478, 154.696, 133.243, 129.589, 129.107, $128.563,69.815,61.978,57.872,34.531,27.965$.

\section{2-(benzoyloxy)- $N$-methylethan-1-aminium chloride}<smiles>O=C(OCCNCl)c1ccccc1</smiles>

A $25 \mathrm{~mL}$ round bottom flask was charged with 2-((tertbutoxycarbonyl)(methyl)amino)ethyl benzoate $(2.3 \mathrm{~g}, 8.2 \mathrm{mmol})$ follow by the addition of $4 \mathrm{M}$ acetyl chloride in anhydrous ethanol $(10 \mathrm{~mL}$, pre-prepared in ice bath). The resulting mixture was stirred under room temperature for 2 hours. Meanwhile, TLC showed starting material completely consumed and a new product with higher polarity was formed. After the removal of solvent by rotary evaporation, white crystals ( $1.5 \mathrm{~g}, 6.9 \mathrm{mmol}, 84 \%$ yield $)$ was formed as final product.

ESI-MS: $[\mathrm{M}+\mathrm{H}]^{+}=180.3$.

${ }^{1}$ H-NMR (300 MHz, DMSO-d6) $\delta: 8.128$ (d, $\left.J=7.5 \mathrm{~Hz}, 2 \mathrm{H}\right), 7.690(\mathrm{t}, J=7.5 \mathrm{~Hz}, 1 \mathrm{H})$, $7.545\left(\mathrm{~d}, J_{1}=7.5 \mathrm{~Hz}, J_{1}=7.5 \mathrm{~Hz}, 2 \mathrm{H}\right), 4.560(\mathrm{t}, J=5.1 \mathrm{~Hz}, 2 \mathrm{H}), 3.620(\mathrm{t}, J=5.1 \mathrm{~Hz}$, 2H), 3.499 (s, 3H). 
${ }^{13} \mathbf{C}\left\{{ }^{1} \mathbf{H}\right\}-N M R$ (75 MHz, DMSO-d6) $\boldsymbol{\delta}:$ 165.536, 133.509, 129.682, 129.188, 128.570, $66.932,60.342,58.113$

\section{Conclusion}

In this manuscript, we observed that the 2-aminoethyl benzoate is unstable in the form of free amine and it would like to perform a sequential rearrangement to $\mathrm{N}$-(2hydroxyethyl)benzamide. To overcome this potential rearrangement reaction in organic synthesis, we introduced a "one-pot synthesis" by adding 2-(benzoxyloxy)ethanaminium chloride, some kind of base and an alkylation reagent all together into an appropriate solvent.

Furthermore, we also introduced a new synthetic methodology that could obtain pure $\mathrm{N}$ monoalkylated ethanol amine derivatives via a deprotonation of Boc protected amine and a sequential addition of alkylation reagent. Compared with traditional synthetic routes, this new synthetic route successfully avoided the possible formation of $N, N$-dialkylated byproduct.

Finally, what need to be emphasized is that the methodology described in this manuscript was an accidental discovery from a drug synthesis. Due to the limitation of time, only few entries were attempted.

\section{References}

(1) In Ullmann's Encyclopedia of Industrial Chemistry.

(2) Calatayud, J., M.D., D.D.S., Ph.D.; González, Á., M.D., D.D.S., Ph.D. Anesthesiology: The Journal of the American Society of Anesthesiologists 2003, 98, 1503.

(3) Wang, L.-M.; Morioka, Y.; Jenkinson, K.; Wheatley, A. E. H.; Saito, S.; Naka, H. Scientific Reports 2018, 8, 6931.

(4) Elangovan, S.; Neumann, J.; Sortais, J.-B.; Junge, K.; Darcel, C.; Beller, M. Nature Communications 2016, 7, 12641.

(5) Enyong, A. B.; Moasser, B. The Journal of Organic Chemistry 2014, 79, 7553.

(6) Yan, T.; Feringa, B. L.; Barta, K. Science Advances 2017, 3, eaao6494.

(7) Midya, S. P.; Mondal, A.; Begum, A.; Balaraman, E. Synthesis 2017, 49, 3957.

(8) Sorribes, I.; Junge, K.; Beller, M. Journal of the American Chemical Society 2014, 136,14314

(9) Zhang, Q.; Fu, M.-C.; Yu, H.-Z.; Fu, Y. The Journal of Organic Chemistry 2016, 81, 6235.

(10) Sheehan, J. C.; Hess, G. P. Journal of the American Chemical Society 1955, 77, 1067.

(11) López-Alonso, J. P.; Diez-García, F.; Font, J.; Ribó, M.; Vilanova, M.; Scholtz, J. M.; González, C.; Vottariello, F.; Gotte, G.; Libonati, M.; Laurents, D. V. Bioconjugate Chemistry 2009, 20, 1459.

(12) Nakajima, N.; Ikada, Y. Bioconjugate Chemistry 1995, 6, 123.

(13) Sheehan, J. C.; Hlavka, J. J. The Journal of Organic Chemistry 1956, 21, 439.

(14) In Encyclopedia of Reagents for Organic Synthesis.

(15) Paul, R.; Anderson, G. W. Journal of the American Chemical Society 1960, 82, 4596.

(16) Caldwell, N.; Campbell, P. S.; Jamieson, C.; Potjewyd, F.; Simpson, I.; Watson, A. J.

B. The Journal of Organic Chemistry 2014, 79, 9347. 
(17) Kerr, J. A. Chemical Reviews 1966, 66, 465. 